〔Med. Entomol. Zool. Vol. 54 No. 2 p. 177-186 2003〕

\title{
Geographic information systems (GIS) analysis of the distribution of the redback spider Latrodectus hasseltii (Araneae: Theridiadae) in Osaka, Japan
}

\author{
Naoko Ninei ${ }^{1)}$, Masahiro Yoshida ${ }^{2)}$, Mutsuo Kobayashi ${ }^{11}$, Hiroyuki Kaneta ${ }^{3)}$, \\ Ryota Shimamura ${ }^{3)}$ and Noriaki AGUI ${ }^{1)}$ \\ 1) Department of Medical Entomology, National Institute of Infectious Diseases, \\ 1-23-1 Toyama, Shinjuku-ku, Tokyo, 162-8640 Japan \\ 2) Laboratory of Medical Entomology, Osaka Prefectural Institute of Public Health, \\ 1-3-69 Nakamichi, Higashinari-ku, Osaka, 537-0025 Japan \\ 3) Geographic Information Systems Institute, Pasco Corporation, Higashiyama Building $4 F$, \\ 1-1-2 Higashiyama, Meguro-ku, Tokyo, 153-0043 Japan
}

(Received: 7 November 2002; Accepted: 31 March 2003)

\begin{abstract}
Since the redback spider, Latrodectus hasseltii Thorell, was first confirmed in November 1995 in the Osaka Bay area in Japan and became established in high density in areas adjacent to the Kansai International Airport, its distribution range continues to expand. Based on the outcome of the redback spider surveys, we implemented address matching and tabulated the survey year, the address of confirmed infested sites and number of webs by year using GIS computer software and digital maps. We furthermore mapped the expanded areas of the spider infestation by year and address and produced density distribution maps for each year from 1995 to 2001 and a map for the period of the surveillance. In addition, since biting cases have been reported, we examined the relationship between the spider density and the number of biting cases. From our GIS analysis it became clear that the distribution range of the redback spider clearly continues to expand in Osaka Prefecture and the expansion of the spider occurred gradually in some coastal areas and dispersed from the densely distributed areas to the more inner areas in Osaka Prefecture. These analyses also show that the number of biting cases by the redback spider will increase in Osaka and surrounding prefectures infested with redback spiders.
\end{abstract}

Key words: Latrodectus hasseltii, redback spider, infestation, Osaka, geographic information systems

\section{INTRODUCTION}

Generally speaking, spiders can be divided into two groups; those that have ubiquitous distribution and those with local distribution. Latrodectus spiders are distributed widely throughout the world, having been confirmed as far north as $50^{\circ}$ in Russia. In the Southern Hemisphere they have spread as far as the southern extremities of the continents (White et al., 1995). Taxonomic work on the genus is progressing, though its classification has yet to be established. Meanwhile, they have not been confirmed north of Northern France in Western Europe or north of $40^{\circ}$ in North America.

The strongly venomous Latrodectus hasseltii Thorell is known, depending on its location, by various local names such as redback spider, jockey spider, murrangura, kapara and kana-jeri. Until recently it was thought to inhabit tropical to temperate areas, especially in the Southern Hemisphere including Australia, New 
Zealand, New Caledonia, Bismarck Archipelago, Polynesia, Sulawesi, Sumatra and India (Levi, 1959; Kavale,1986; Ori et al., 1996; White et al, 1995). However, there were suspicions that a spider collected in September 1995 along the waterfront of Osaka Bay $\left(34.5^{\circ} \mathrm{N}, 135.5^{\circ} \mathrm{E}\right)$ was a species brought in from abroad and it was identified in November of that year to be the redback spider (Kanazawa et al., 1996; Nishikawa and Kanazawa, 1996). The tolerance of redback spiders collected in Osaka to low temperature was tested, and the possibility of hibernation and the spread of the spider to wider areas in Japan were suggested (Matsuse et al., 1997, 1999). Since its establishment was first confirmed in Japan, its range continued to expand. Surveys have been conducted continuously since the end of 1995 and, now that these data have been accumulated, it has become possible to ascertain distribution characteristics such as the speed of range expansion, density of the spiders and expansion pattern. The establishment and spread of an introduced venomous spider have seldom been documented in Japan and also in the world. In this study, an integrated analysis of the results of the redback spider surveys was carried out using geographic information systems (GIS). The conditions of distribution were indicated on the charts so that they can be visually and spatially grasped in detail as a time-series. Focusing on local dispersion, we divided the area into three zones. GIS makes it possible for researchers and government agencies to ascertain and monitor the present distribution and conditions of expansion easily and accurately. The GIS analysis also contributes to devising preventive measures and provides information on bio-risk management for the local government.

\section{Materials AND Methods}

\section{Sources of data}

From 1995 through 2001, information of redback spider infestation was provided by local residents and others to public health centers in Osaka Prefecture and Sakai City. In addition, on-site surveys were conducted by the Osaka Prefectural Institute of Public Health to confirm newly infested sites and the surrounding areas. A comprehensive survey of the spider was also carried out at new housing developments and subdivisions around the infested areas all year around. The mean survey days per year were forty-six. Identification of the redback spider was done at the survey site by the characteristic color pattern on the dorsal and ventral abdomen of the spider. The developmental stage of the spider and the numbers of spiders and newly constructed webs which were clearly identified by the characteristic gloss of web thread, were recorded. When the spider was not observed directly, the number of its characteristic webs was recorded. The number of new webs is equivalent to at least one adult or larval female per web, because male spiders never construct webs. All the data were tabulated as Excel files (Microsoft); items included were the survey date, address of the infested site, postalcode, type of artifacts at the infestation sites (e.g., street-side gutter, drainage ditch cover, fence, overpass, streetlight), land use or facility name, source of data (voluntary report, government survey, etc.), sex, number and stages of the spiders and number of webs. In this study, we focused on three surveillance components: the number of infested sites, total number of webs, and webs per site (the spider density) by municipality. The number of webs per site is tentatively defined as the spider density.

Tools used for GIS processing and analysis

We set up the surveys in order to be able 
to cover a wide area using ArcView (ESRI) as GIS software. As GIS analysis materials, the survey date, survey site number of webs per site and density of infested sites from the results of these surveys were compiled in Excel.

As maps that can be used on PC computers, we used Pasco Digital Maps (PDM by Pasco, Tokyo), which make it possible to specify secondary divisions of municipalities and postalcode areas in the Japanese address system. We used Excel for preparation and tabulation of preliminary data, and converted the data using software applications that can be opened in ArcView, and then matched addresses of the survey sites by the use of the software package "Pasco Market Analysis".

The spider infestation summed up by year and local municipality

We tabulated the number of the infested sites, the number of webs and average number of webs per infested site in Osaka Prefecture by each year and local municipality. The location of the municipality infested with the redback spider is shown in the figures. The names of municipalities are arranged in the table according to priority of the coastal areas from north to south, inland areas from north to south and, the northern area of Osaka Prefecture from south to north.

\section{Expansion of redback spider distribution by the year}

We tabulated the number of webs by the year and municipality division (Chome or Cho in Japanese address system) and prepared a total of six maps including one map, which was made from data combined with 1995 and 1996, and the other five for each year from 1997 through 2001. An expansion map of the redback spider was made by overlaying 6 maps and selecting the earliest sites of infestation in these maps.

\section{Distribution maps with infestation density}

We divided the number of webs per site into three categories, $1-50,51-100$, or $101+$, by year and by Chome or Cho and prepared distribution maps with infestation density. Overlaying these, we selected the highest level of infested site density by Chome or Cho and prepared a maximum density distribution chart from 1995 through 2001.

\section{RESULTS}

\section{Distribution and expansion of the redback} spider in Osaka Prefecture

By the time the first full-scale survey was conducted in 1996, collections were made at 180 sites in 14 municipalities (Tables 1-3, Fig. 1). There was a total of 1,101 webs, the average number of webs at collection sites was 6.1/site (range 1.031.3) and for the most part were at a low level of less than 50. Although numerical disparities are present year by year due to factors related to the ecology of the spider and fundamental limitations of actual onsite surveys, a rapid increase was observed in confirmed infestation sites, 490 and 298, and total web count, 5,082 and 6,598 in 2000 and 2001 , respectively. Infested sites are being confirmed from Sakai City (1) to Hannan City (10) along the coastal area in south Osaka Prefecture, in a continuous manner. Further inland, there are some cities, such as Tondabayashi City (15), that are discovered every year as well as cities infested with high spider densities of $30-90$ per site, although there were a few confirmed sites. Izumi City (16) where infestations have been confirmed since 1998 is not located adjacent to Osaka Bay and is also adjacent to Takaishi City (2), Izumiotsu City (3), Kishiwada City (5), and these cities have many infested sites, and the present distribution is possibly due to contiguous expansion. The redback spider infestations in other regions are no more than confirmation of chance, sporadic distribution. There have also been a few confirmed sites in the cities from Suminoe, Osaka City (19) to Suita City (27) in the area north of 


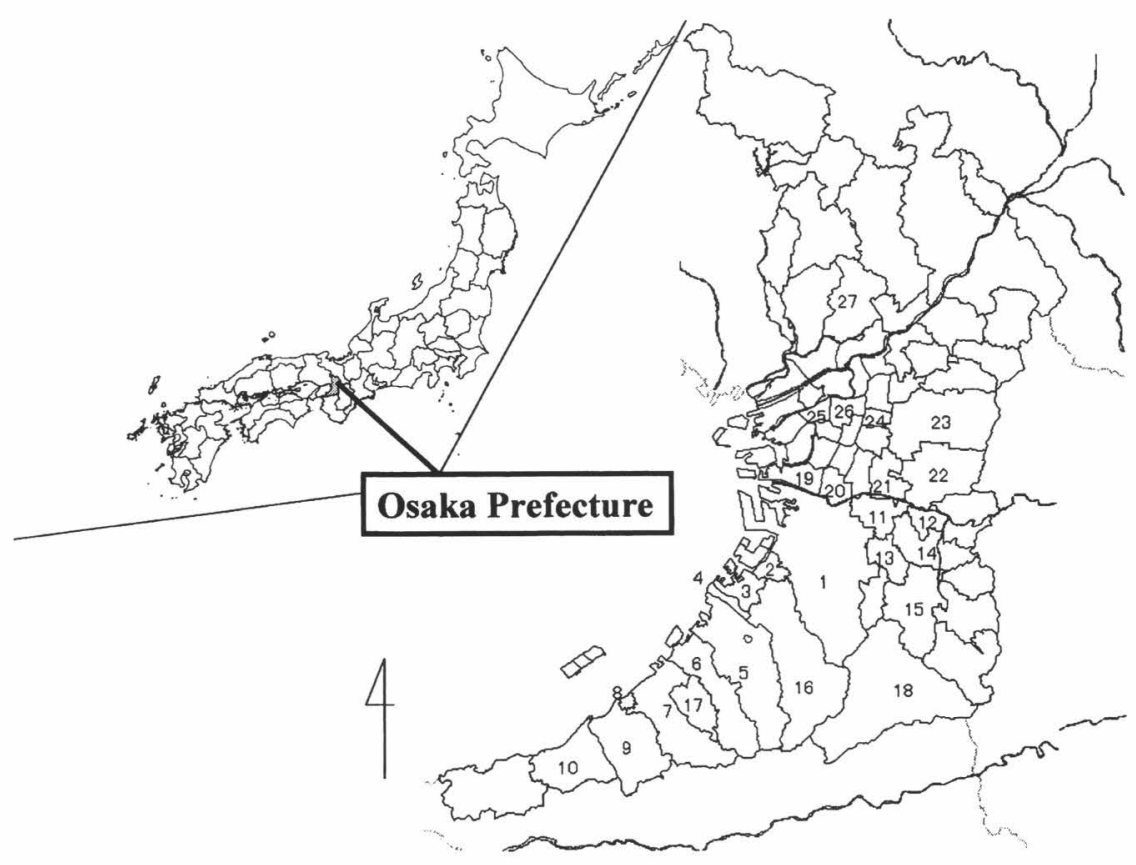

Fig. 1. Survey area of redback spider in Osaka Prefecture. Numbers in Fig. 1 correspond to the city or town number in Tables 1-3.

Osaka Prefecture and the number of webs per site is 13.0 or less, mostly in the range of $1.0-2.0$.

Area division from the perspective of infestation pattern

We also extracted the tendency of distribution characteristics based on the maps that we had prepared, and indicated the infestation pattern geographically. Based on these results, we divided the area into four zones taking into account the timeseries changes of the spider in Osaka Prefecture. The distribution area consists of the earliest contiguous infestation (zone (1)-a), later contiguous infestation (zone (1)-b), non-contiguous infestation (zone (2)) and scarcely infested (zone (3)) (Fig. 2).

Distribution of redback spider from the perspective of the dispersal process

The infestation areas of the spider spread to artificially modified areas such as land reclamation sites in the Osaka Bay area and especially to zone (1). In zone (1)-a in 1997, the expansion was observed into areas adjacent to previously infested areas and, in 1998, there was further expansion so that the areas of confirmed infestations entirely covered zone (1)-a as a whole. In zone (1)-b, there was scattered expansion in 1997; however, there was rapid expansion in 2000 and infested sites were also confirmed virtually throughout the zone while some areas remained unaffected with no confirmed sightings.

Waterfront infestations were confirmed in the central zone (2) in 1996; however, expansion into adjacent areas and, beginning in 1998, the infested areas expanded about $15 \mathrm{~km}$ inland from the waterfront. There was spotty and scattered distribution of the spider showing both contiguous and non-contiguous expansion. In 2001, still, there was contiguous expansion centered in the areas of noncontiguous distribution along private railway lines as far as $5-10 \mathrm{~km}$ inland from the waterfront and into areas further inland as well.

In the northern zone (3), the redback spider was observed only at 4 sites and 
Table 1. Number of confirmed infested sites of redback spider of 27 districts in Osaka, Japan.

\begin{tabular}{|c|c|c|c|c|c|c|c|c|c|}
\hline & City or Town & 1995 & 1996 & 1997 & 1998 & 1999 & 2000 & 2001 & Total \\
\hline \multirow{10}{*}{$\begin{array}{c}\text { Coastal } \\
\text { area }\end{array}$} & 1 Sakai C & + & 9 & 4 & 20 & 21 & 44 & 115 & 213 \\
\hline & 2 Takaishi C & + & 17 & 12 & 3 & 1 & 31 & 9 & 73 \\
\hline & 3 Izumiotsu $\mathrm{C}$ & + & 17 & - & 18 & 2 & 23 & 28 & 88 \\
\hline & 4 Tadaoka T & + & 7 & - & 4 & 1 & - & - & 12 \\
\hline & 5 Kishiwada C & + & 24 & 3 & 6 & 12 & 126 & 44 & 215 \\
\hline & 6 Kaizuka C & + & 49 & 10 & 16 & 4 & 82 & 9 & 170 \\
\hline & 7 Izumisano C & + & 30 & 35 & 34 & 7 & 104 & 10 & 220 \\
\hline & 8 Tajiri T & + & 7 & 14 & 8 & - & 12 & 5 & 46 \\
\hline & 9 Sennan C & + & 7 & 15 & 17 & 1 & 25 & 1 & 66 \\
\hline & 10 Hannan $\mathrm{C}$ & 0 & 3 & 21 & 9 & 1 & 18 & - & 52 \\
\hline \multirow{8}{*}{$\begin{array}{c}\text { Inland } \\
\text { area }\end{array}$} & 11 Matsubara C & 0 & 0 & 0 & 1 & 0 & 0 & 0 & 1 \\
\hline & 12 Fujiidera C & 0 & 4 & 0 & 0 & 0 & 0 & 0 & 4 \\
\hline & 13 Mihara $\mathrm{T}$ & 0 & - & - & 3 & 0 & 0 & - & 3 \\
\hline & 14 Habikino $\mathrm{C}$ & 0 & 1 & 0 & 0 & 0 & 0 & 0 & 1 \\
\hline & 15 Tondabayashi C & 1 & 2 & 1 & 1 & 1 & 4 & 27 & 37 \\
\hline & 16 Izumi C & 0 & - & - & 10 & 1 & 10 & 18 & 39 \\
\hline & 17 Kumatori $\mathrm{T}$ & 0 & - & - & 1 & 1 & 4 & - & 6 \\
\hline & 18 Kawachinagano $\mathrm{C}$ & - & - & - & - & - & - & 11 & 11 \\
\hline \multirow{10}{*}{$\begin{array}{c}\text { Osaka C. } \\
\text { and the } \\
\text { north }\end{array}$} & 19 Suminoe, Osaka C & - & - & - & - & - & - & 4 & 4 \\
\hline & 20 Sumiyoshi, Osaka C & - & - & - & - & - & 5 & 0 & 5 \\
\hline & 21 Hirano, Osaka C & - & - & - & 1 & 1 & 1 & 1 & 4 \\
\hline & 22 Higashinari, Osaka C & 0 & 0 & 0 & 0 & 1 & 1 & 0 & 2 \\
\hline & 23 Nishi, Osaka C & - & - & - & - & - & - & 7 & 7 \\
\hline & 24 Chuo, Osaka C & - & - & - & - & - & 0 & 6 & 6 \\
\hline & 25 Yao C & - & - & 1 & 2 & 0 & 0 & 1 & 4 \\
\hline & 26 Higashiosaka C & 1 & 3 & 0 & 0 & 0 & 0 & 0 & 4 \\
\hline & 27 Suita C & 0 & 0 & 1 & 0 & 0 & 0 & 2 & 3 \\
\hline & Total & 2 & 180 & 117 & 154 & 55 & 490 & 298 & 1296 \\
\hline
\end{tabular}

+ , detected but not calculated;

0 , investigated but not detected;

- , not investigated.

was scattered in areas about $20 \mathrm{~km}$ inland from the waterfront prior to 1996. As of 2001, however, infestations were limited to totally 10 areas (only 7 areas shown in Fig. 2) and the areas were small. The spider has not been confirmed across the mountains in Wakayama or Nara Prefectures.

\section{Distribution by density}

Viewing the 6 density distribution maps by year from 1996 and earlier through 2001 (omitted due to lack of space), it is shown that, while most infested sites had a low density of 1-50 webs/site prior to 1996, high-density infestations of $101+$ webs/site expanded especially in the coastal area by 1997 . Though there was considerable expansion in 1998, low-density sites were conspicuous while densities in coastal area stayed high. In 1999, infestations were limited in area but high-density sites were observed inland. In 2000, range expansion was noted in particular in the southern areas and areas of high density were also observed. In 2001, the expansion was observed in the central zone while, at the same time, high-density sites were also seen inland.

The density distribution maps for the entire survey period (Fig. 3) indicate that, in terms of area, there are presently many 
Table 2. Total number of redback spider's webs of 27 districts in Osaka, Japan.

\begin{tabular}{|c|c|c|c|c|c|c|c|c|c|}
\hline & City or Town & 1995 & 1996 & 1997 & 1998 & 1999 & 2000 & 2001 & Total \\
\hline \multirow{10}{*}{$\begin{array}{c}\text { Coastal } \\
\text { area }\end{array}$} & 1 Sakai C & + & 282 & 106 & 160 & 429 & 383 & 2375 & 3735 \\
\hline & 2 Takaishi C & + & 204 & 19 & 6 & 1 & 139 & 177 & 546 \\
\hline & 3 Izumiotsu C & + & 35 & - & 283 & 32 & 53 & 252 & 655 \\
\hline & 4 Tadaoka $\mathrm{T}$ & + & 11 & - & 24 & 1 & - & - & 36 \\
\hline & 5 Kishiwada C & + & 43 & 107 & 184 & 135 & 1442 & 519 & 2430 \\
\hline & 6 Kaizuka C & + & 217 & 264 & 587 & 114 & 454 & 273 & 1909 \\
\hline & 7 Izumisano $\mathrm{C}$ & + & 198 & 873 & 383 & 99 & 988 & 280 & 2821 \\
\hline & 8 Tajiri T & + & 41 & 335 & 278 & - & 115 & 79 & 848 \\
\hline & 9 Sennan C & + & 13 & 88 & 126 & 1 & 947 & 101 & 1276 \\
\hline & 10 Hannan C & 0 & 12 & 49 & 33 & 2 & 184 & - & 280 \\
\hline \multirow{8}{*}{$\begin{array}{l}\text { Inland } \\
\text { area }\end{array}$} & 11 Matsubara C & 0 & 0 & 0 & 1 & 0 & 0 & 0 & 1 \\
\hline & 12 Fjiidera $\mathrm{C}$ & 0 & 7 & 0 & 0 & 0 & 0 & 0 & 7 \\
\hline & 13 Mihara $\mathrm{T}$ & 0 & - & - & 58 & 0 & 0 & - & 58 \\
\hline & 14 Habikino $\mathrm{C}$ & 0 & 1 & 0 & 0 & 0 & 0 & 0 & 1 \\
\hline & 15 Tondabayashi C & 90 & 2 & 29 & 35 & 51 & 210 & 2175 & 2592 \\
\hline & 16 Izumi C & 0 & - & - & 33 & 1 & 140 & 180 & 354 \\
\hline & 17 Kumatori $\mathrm{T}$ & 0 & - & - & 3 & 1 & 10 & - & 14 \\
\hline & 18 Kawachinagano C & - & - & - & - & - & - & 86 & 86 \\
\hline \multirow{10}{*}{$\begin{array}{c}\text { Osaka C. } \\
\text { and the } \\
\text { north }\end{array}$} & 19 Suminoe, Osaka C & - & - & - & - & - & - & 4 & 4 \\
\hline & 20 Sumiyoshi, Osaka C & - & - & - & - & - & 9 & 0 & 9 \\
\hline & 21 Hirano, Osaka C & - & - & - & 1 & 1 & 7 & 2 & 11 \\
\hline & 22 Higashinari,Osaka C & 0 & 0 & 0 & 0 & 1 & 1 & 0 & 2 \\
\hline & 23 Nishi, Osaka C & - & - & - & 26 & - & - & 59 & 59 \\
\hline & 24 Chuo, Osaka C & - & - & - & 0 & - & 0 & 8 & 8 \\
\hline & $25 \mathrm{Yao} \mathrm{C}$ & - & - & 2 & 0 & 0 & 0 & 1 & 29 \\
\hline & 26 Higashiosaka C & 1 & 35 & 0 & & 0 & 0 & 0 & 36 \\
\hline & 27 Suita C & 0 & 0 & 1 & & 0 & 0 & 27 & 28 \\
\hline & Total & 91 & 1101 & 1873 & 2221 & 869 & 5082 & 6598 & 17835 \\
\hline
\end{tabular}

+ , detected but not calculated;

0 , investigated but not detected;

- , not investigated.

locations with a density of fewer than 50 webs/site; however, high-density infestations with $101+$ webs/site were observed in the waterfront areas from the outset of the incursion by the redback spider into the southern zone. High-density sites of 51-100 and $101+$ webs/site were confirmed among the isolated infested areas that are scattered $15-20 \mathrm{~km}$ inland from the bay area in the central zone. All of the infested sites in the northern zone were low-density. Two confirmed cases of biting were reported in the coastal area (see Fig. 3) and both sites showed a high density of the redback spider of more than $101 \mathrm{webs} /$ site.

\section{Discussion}

Various reports have been released regarding the redback spider classification, ecology, toxicity, envenomation, observation cases, discovery situations and so forth; however, the factors relating to distribution of the spiders have only been touched upon in general discussions (Nishikawa and Kanazawa, 1996; White et al., 1995; Kanazawa et al., 1996).

Generally speaking, it is necessary to examine the movement and establishment factors involved in the distribution and expansion of confirmed sites (Yoshikura, 
Table 3. Number of redback spider's webs/site in 27 disricts in Osaka, Japan.

\begin{tabular}{|c|c|c|c|c|c|c|c|c|}
\hline & City or Town & 1995 & 1996 & 1997 & 1998 & 1999 & 2000 & 2001 \\
\hline \multirow{10}{*}{$\begin{array}{c}\text { Coastal } \\
\text { area }\end{array}$} & 1 Sakai C & + & 31.3 & 26.5 & 8.0 & 20.4 & 8.7 & 20.7 \\
\hline & 2 Takaishi C & + & 12.0 & 1.6 & 2.0 & 1.0 & 4.5 & 19.7 \\
\hline & 3 Izumiotsu C & + & 2.1 & - & 15.7 & 16.0 & 2.3 & 9.0 \\
\hline & 4 Tadaoka T & + & 1.6 & - & 6.0 & 1.0 & - & - \\
\hline & 5 Kishiwada C & + & 1.8 & 35.7 & 30.7 & 11.3 & 11.5 & 11.8 \\
\hline & 6 Kaizuka C & + & 4.4 & 26.4 & 36.7 & 28.5 & 5.5 & 30.3 \\
\hline & 7 Izumisano $\mathrm{C}$ & + & 6.6 & 24.9 & 11.3 & 14.1 & 9.5 & 28.0 \\
\hline & 8 Tajiri T & + & 5.9 & 23.9 & 34.8 & - & 9.6 & 15.8 \\
\hline & 9 Sennan & + & 19 & 5.9 & 7.4 & 1.0 & 37.9 & 101.0 \\
\hline & 10 Hannan C & 0 & 4.0 & 2.3 & 3.7 & 2.0 & 10.2 & - \\
\hline \multirow{8}{*}{$\begin{array}{c}\text { Inland } \\
\text { area }\end{array}$} & 11 Matsubara C & 0 & 0 & 0 & 1.0 & 0 & 0 & 0 \\
\hline & 12 Fujiidera C & 0 & 1.8 & 0 & 0 & 0 & 0 & 0 \\
\hline & 13 Mihara $\mathrm{T}$ & 0 & - & - & 19.3 & 0 & 0 & - \\
\hline & 14 Habikino $\mathrm{C}$ & 0 & 1.0 & 0 & 0 & 0 & 0 & 0 \\
\hline & 15 Tondabayashi C & 90.0 & 1.0 & 29.0 & 35.0 & 51.0 & 52.5 & 58.2 \\
\hline & 16 Izumi C & 0 & - & - & 3.3 & 1.0 & 14.0 & 10.0 \\
\hline & 17 Kumatori $\mathrm{T}$ & 0 & - & - & 3.0 & 1.0 & 2.5 & - \\
\hline & 18 Kawachinagano C & - & - & - & - & - & - & 7.8 \\
\hline \multirow{9}{*}{$\begin{array}{c}\text { Osaka C. } \\
\text { and the } \\
\text { north }\end{array}$} & 19 Suminoe, Osaka C & - & - & - & - & - & - & 1.0 \\
\hline & 20 Sumiyoshi, Osaka C & - & - & - & - & - & 1.8 & 0 \\
\hline & 21 Hirano, Osaka C & - & - & - & 1.0 & 1.0 & 7.0 & 2.0 \\
\hline & 22 Higashinari,OsakaC & 0 & 0 & 0 & 0 & 1.0 & 1.0 & 0 \\
\hline & 23 Nishi, Osaka C & - & - & - & - & - & - & 8.4 \\
\hline & 24 Chuo, Osaka C & - & - & - & - & - & - & 1.3 \\
\hline & 25 Yao C & - & - & 2.0 & 13.0 & 0 & - & 1 \\
\hline & 26 Higashiosaka C & 1.0 & 11.7 & 0 & 0 & 0 & 0 & 0 \\
\hline & 27 Suita C & 0 & 0 & 1.0 & 0 & 0 & 0 & 13.5 \\
\hline
\end{tabular}

+ , detected but not calculated;

0 , investigated but not detected;

-, not investigated.

1987). As regards the movement factors, there are many possible means of conveyance such as aerial flight by web strands or wind and various vehicles, such as aircraft, boats, railway trains, automobiles, motorcycles, bicycles and unspecified means of transportation, though there are no detailed reports (Forster, 1984). In addition, although temperature, precipitation, feeding habits, amount of prey and so forth have been pointed out as establishment factors, virtually no detailed information is available (Yoshikura, 1987; Forster, 1995).

Various maps resulting from GIS analyses, at the moment, have clearly showed the expansion of the infested sites and the distribution of spider densities, making it possible to detect uneven distribution and local dispersion. In Brisbane uneven dispersion of redback spider was recognized before about 20 years, but there is a contiguous distribution in urban district of Brisbane at this moment. It may occur as contiguous distribution in Osaka Prefecture in the near future. It is therefore necessary to set up a monitoring system on both a constant and a periodic basis.

Locations confirmed to be the infestation sites of the redback spider include newly constructed facilities with sparse vegetative cover as the result of artificial modification such as the development of green or forested areas. Invasion of red- 


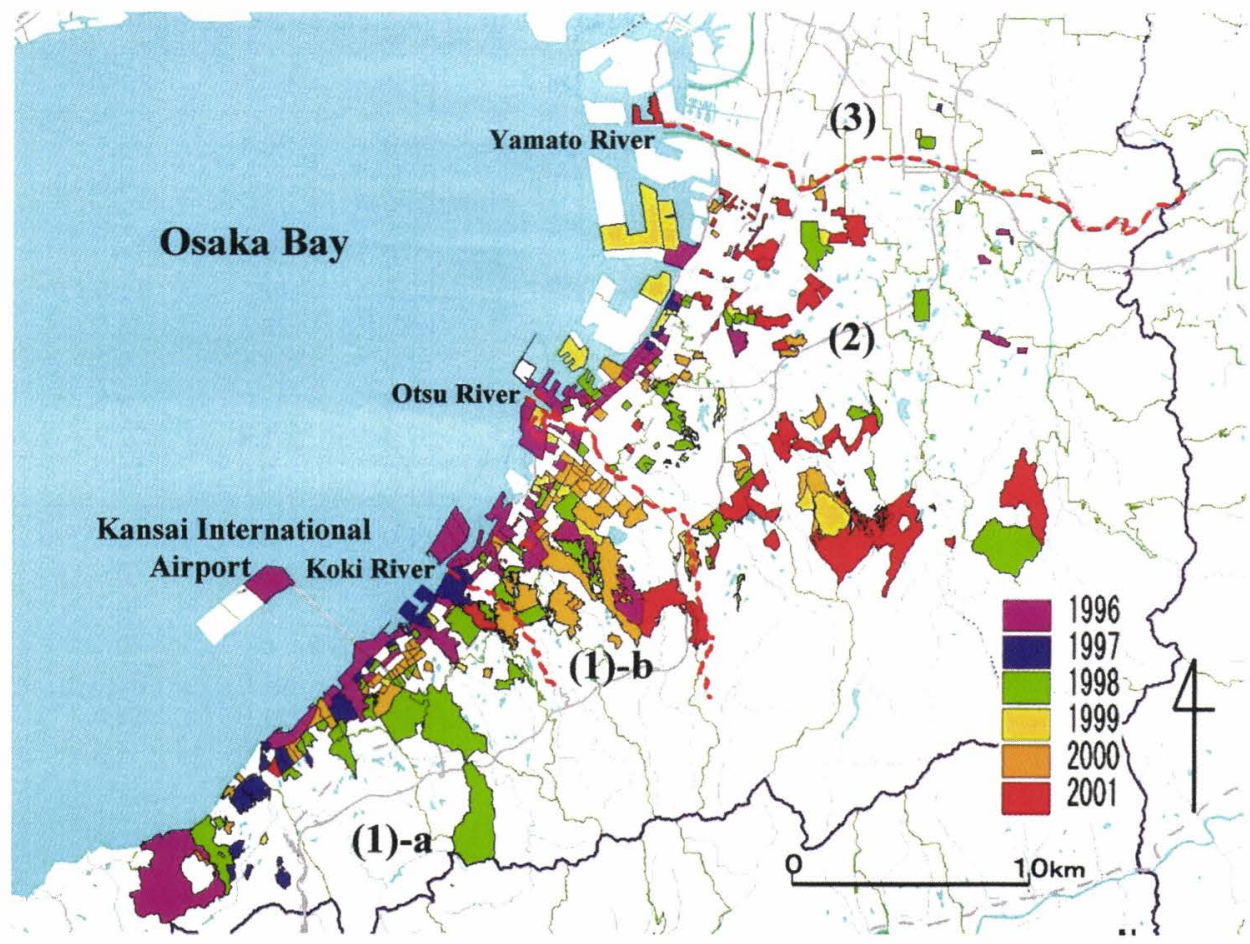

Fig. 2. Expansion of the distribution of sites of redback spiders, by year from 1996 and earlier to 2001. A red dash line shows the boundary of zone division based on the characteristics of the distribution of the redback spider in Osaka, Japan. For further detail, see the text.

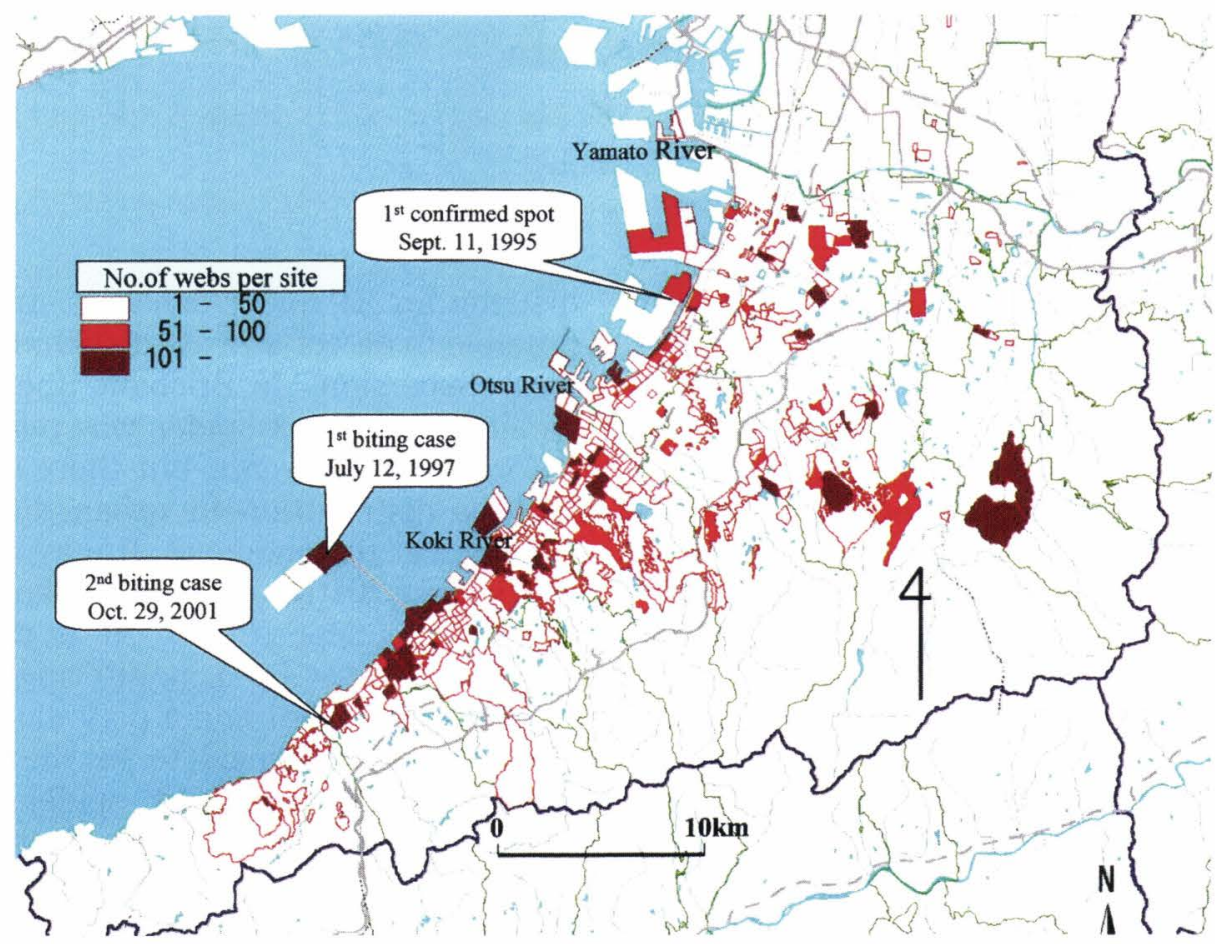

Fig. 3. Density of redback spider in infested sites (number of webs per site) for the entire surver period. 
back spiders has been essentially unconfirmed in old sections of urban districts, although attention will be necessary so as to observe future trends.

The infestation patterns of the redback spider in Osaka show contiguous expansion in coastal areas and non-contiguous expansions in inland areas. Analysis of the local disparities in spider distribution will undoubtedly be beneficial in elucidating the factors controlling the distribution of the redback spider, and in preventing accidental biting by the spider in the future.

Temperature is an important factor in determining habitat suitable for the redback spider (Forster, 1984; Matsuse et al., 1997; Matsuse et al., 1999) and release of spider offspring from the egg sac is not observed at temperatures higher than $35^{\circ}$ $\mathrm{C}$ or lower than $16^{\circ} \mathrm{C}$. Release from the egg sac at an early stage of the larvae occurs 20 days after oviposition at $30^{\circ} \mathrm{C}$ and $40-50$ days at $20^{\circ} \mathrm{C}$, the required time lengthening as the air temperature drops (Matsuse et al., 1999; Tanaka, 1993). Annual mean temperature from 1971 to 2000 of Osaka City was $16.5^{\circ} \mathrm{C}$. The monthly mean temperatures changed from $5.8^{\circ} \mathrm{C}$ to $28.4^{\circ} \mathrm{C}$ (Japan Meteorological Agency, 2001a, b). If temperatures especially higher than $20^{\circ} \mathrm{C}$ of daily mean temperatures, continued for 141 days per year, it will offer the optimal temperature conditions for the establishment of the infested area among data shown by the Japanese weather bureaus.

We were able to recognize the differences in infestation patterns and density of the redback spider in the study area. These are thought to be due to different environmental factors. Since the biting cases of the redback spider occur in highdensity areas of $101+$ web/site, it will be necessary to establish a critical spider density to arouse the attention of the public. The present GIS-based surveys and the mapping of the results are unprecedented not only in Japan but throughout the world and will serve as fundamental mate- rials to understand the applicability of GIS for evaluating spider distribution and density, and there is a need to continue surveillance using this method.

\section{ACKNOWLEDGEMENTS}

We thank Welfare Environmental Health Division, Department of Public Health and Welfare, Osaka Prefectural Government and Environmental Sanitation Division, Sakai City Public Health Center for their technical supports. We wish to thank Drs. H. Kosaka and T. Sekine (Department of Geography, Nihon University), Dr. K. Hirata (Geographic Information Systems Institute, Pasco Co.) and Dr. T. Takeuchi (Keio University) who helped us in various ways during the course of this study. This study was supported, in part, by Health Sciences Research Grants in Research on Emerging and Reemerging Infectious Diseases from the Ministry of Health, Labor and Welfare in Japan and was supported by a Grant-inAid for Scientific Research from the Ministry of Education, Culture, Sports, Science and Technology.

\section{REFERENCES}

Forster, L. 1984. The Australian redback spider (Latrodectus hasselti): its introduction and potential for establishment and distribution in New Zealand. In: Commerce and the Spread of Harmful Pests and Disease Vectors (ed., Laird, M.), pp. 273-289. Praegar Press, New York.

Forster, L. 1995. The behavioural ecology of Latrodectus hasselti (Thorell), The Australian redback spider (Araneae: Theridiidae): a review. Rec. West. Aust. Mus., Suppl. 52: 13-24.

Japan Meteorological Agency, 2001a. Climate table of Japan, vol. 1. Monthly Data. Tokyo, Japan.

Japan Meteorological Agency, 2001b. Normals for the Period 1971-2000. (CD-Rom; OOS-084A). Supervised by Meteorological Agency, Meteorological Works Support Center.

Kanazawa, I., Nishikawa, Y. and Tomizawa, O. 1996. Introduction of the redback spiders to Japan. Nat. Study, 42: 64-67 (In Japanese). 
Kavale, J. 1986. The comparative biology of two Latrodectus species. M. Sc. Dissertation, Univ. of Otago, Duendin, New Zealand.

Levi, H. W. 1959. The spider genus Latrodectus (Araneae, Theridiidae). Trans. Am. Microsc. Soc., 78: 743.

Matsuse, I. T., Kamimura, K. and Yoshida, M. 1999. The tolerance of Latrodectus hasseltii (Araneae: Theridiidae) to low temperatures. Med. Entomol. Zool., 50: 71-73.

Matsuse, I. T., Takeda, C. M., Kamimura, K. and Yoshida, M. 1997. Tolerance of Latrodectus hasseltii (Araneae: Theridiidae) to low temperatures in Japan. Med. Entomol. Zool., 48: 117-122.

Nishikawa, Y. and Kanazawa, I. 1996. Identification of the redback spider in Osaka, Japan and safety measures against its venom. Jpn. J. Environ. Entomol. Zool., 7: 214-223 (In Japanese).

Ori, M., Shinkai, E. and Ikeda, H. 1996. Introduction of widow spiders into Japan. Med. Entomol. Zool. 47: 111-119 (In Japanese with English abstract).

Tanaka, K. 1993. The role of diapause in subtropical zone: in the case of grey house spider, Achaearanea tepiariorum. Arachnology, 42: 196 (In Japanese).

White, J., Cardoso, J. L. and Fan, H. W. 1995. Clinical toxicology of spider bites. In: Handbook of Clinical Toxicology of Animal Venoms and Poisons (ed. Meier, J. and White, J.), pp. 259-329. CRC Press, New York.

Yoshikura, M. 1987. The Biology of Spiders. 613 pp. Japan Scientific Societies Press, Tokyo (In Japanese). 